\title{
Influence of Gratitude and Materialism on Two Different Conceptualizations of Subjective Well-being*
}

\section{Influencia de la gratitud y el materialismo en dos conceptualizaciones diferentes del bienestar subjetivo}

Received: 02 February 2014 | Accepted: 23 June 2016

\author{
Rogelio Puente-Díaz ${ }^{a}$ \\ Universidad Anahuac México, Mexico \\ ORCID: http://orcid.org/0000-0001-6777-7103 \\ Judith Cavazos-Arroyo \\ Universidad Popular Autónoma del Estado de Puebla, \\ Mexico \\ ORCID: http://orcid.org/0000-0002-6258-289X
}

a Correspondence author. Email: rogelio.puente@anahuac.mx

How to cite: Puente-Díaz, R., \& Cavazos-Arroyo, J. (2019). Influence of gratitude and materialism on two different conceptualizations of subjective well-being. Universitas Psychologica, 18(3), 1-9. https:// doi.org /10.11144/Javeriana.upsy18-3.igmt

\begin{abstract}
The present investigation examined the influence of materialism and gratitude on subjective well-being under two different conceptualizations of this construct: subjective well-being as a construct with three independent components and subjective well-being as a second other factor with three first order factors. 386 participants from Mexico completed a battery of questionnaires measuring gratitude, materialism, positive and negative affect and life satisfaction. Results showed a negative influence of materialism on positive affect, life satisfaction and overall sense of subjective well-being and a positive influence on negative affect. Gratitude had a positive influence on positive affect, life satisfaction and overall sense of subjective well-being. Results also showed that gratitude did not influence negative affect directly, but indirectly through its influence on overall sense of subjective well-being. The implications of our findings were discussed.

Keywords

Subjective well-being; gratitude; materialism; second order factor.
\end{abstract}

\section{RESUMEN}

Esta investigación examinó la influencia del materialismo y la gratitud en el bienestar subjetivo bajo dos conceptualizaciones de este constructo: bienestar subjetivo como constructo con tres componentes independientes y bienestar subjetivo como un factor de segundo orden con tres factores de primer orden. 386 participantes completaron una batería de cuestionarios midiendo gratitud, materialismo, afecto positivo y negativo y satisfacción con la vida. Los resultados mostraron una influencia negativa del materialismo en el afecto positivo, satisfacción con la vida y la sensación general de bienestar subjetivo y una influencia positiva en el afecto negativo. La gratitud tuvo un efecto positivo en el afecto positivo, satisfacción con la vida, y la sensación general de bienestar subjetivo. Los resultados también mostraron que la gratitud no afecta directamente el afecto negativo, pero indirectamente a través de 
su efecto en la sensación general de bienestar subjetivo. Las implicaciones de nuestros resultados fueron discutidas.

Palabras clave

Bienestar subjetivo; gratitud; materialismo; factor de segundo orden.

Psychology has recently shown more enthusiasm for understanding the positive aspects of life (Fredrickson \& Joiner, 2018). Among the different positive aspects of life, subjective well-being has been widely examined (Gruber \& Moskowitz, 2014; Lucas \& Diener, 2008). Recently, however, researchers have identified five different conceptualizations of subjective well-being to exemplify the inconsistencies in the conceptualization and operationalization of the construct (Busseri, 2018; Busseri \& Sadava, 2011). Additionally, these researchers call for less ambiguity in the conceptualization and operationalization of thisconstruct to examine, with accuracy, some of its predictors (Busseri \& Sadava, 2011). The purpose of our investigation is, then, to answer this call by comparing and contrasting the effect of materialism and gratitude on two different conceptualizations of subjective well-being. In order to accomplish this goal, we first review the different conceptualization of subjective wellbeing followed by a discussion of how materialism and gratitude might act as predictors.

\section{Conceptualizations of subjective well-being}

In a research article (Busseri \& Sadava, 2011), researchers identified five different conceptualizations of subjective well-being and suggested that inconsistencies in conceptualization between studies have led to inconclusive findings. For the purpose of our investigation, we focus on explaining and examining two of these conceptualizations. In the first conceptualization, subjective wellbeing is treated as a construct with three different, separate components: life satisfaction, positive and negative affect. Research within this conceptualization has focused on understanding the unique and common predictors of each of the three components. It is assumed that it is important to assess each of three components separately to provide an accurate description of subjective well-being and to examine the common and unique predictors of each component (Busseri, 2018).

In the second conceptualization, subjective well-being is treated as a higher order factor, reflected in three first-order factors: life satisfaction, positive affect and negative affect, suggesting a hierarchical structure. This model proposes that a higher order factor, subjective well-being, is responsible for the associations between life satisfaction, positive affect, and negative affect. Research within this conceptualization has found empirical support for the presence of a higher order factor with strong factor loadings from the first-order factors (Busseri \& Sadava, 2011). For the sake of clarity, we use the term overall sense of subjective wellbeing to refer to this higher order factor.

Busseri and Sadava (2011) make several suggestions for future research, which include choosing and justifying the use of any of the different conceptualizations of subjective well-being, examining predictors of subjective well-being under different conceptualizations, and comparing and contrasting results obtained from different conceptualization within the same investigation. We seek to answer this call by examining the influence of gratitude and materialism on subjective well-being under two conceptualizations: subjective well-being as a construct with three different, separate components and subjective well-being as a higher order factor, reflected in three first-order factors. Comparing and contrasting the influence of predictors under two different conceptualizations would allow us to establish if any of the two predictors have unique relations with any of the three separate components of subjective wellbeing, independent of the higher order subjective well-being factor (Busseri \& Sadava, 2011). Now, we turn of attention to the role of materialism as a predictor of subjective well-being. 


\section{Materialism}

Materialism is conceptualized as a value that reflects the belief that possessions are important in one's life (Richins, 2004). The importance of material values lies in that individual differences in the endorsement materialism are expected to lead to different cognitive, affective and behavioral outcomes (Kasser, 2016), including subjective well-being. Thus, materialism has been proposed as a predictor of subjective well-being.

Across different investigations, materialism seems to exert a negative effect on subjective well-being (Burroughs \& Rindfleisch, 2002). However, in our opinion, many of these investigations have had the limitation that subjective well-being has not been conceptualized consistently (Burroughs \& Rindfleisch, 2002). That is, some investigations have focused mainly on assessing the impact of materialism on judgments of general and domain specific satisfaction, paying less attention to the influence of materialism on positive and negative affect. Similarly, to our knowledge, not a single study has examined the influence of materialism on subjective well-being under the hierarchical conceptualization of the construct. Thus, the present investigation tries to overcome some of these limitations by testing the effect of materialism on each of the three separate components of subjective well-being and on the second order factor of overall sense of subjective well-being, controlling for the known effects of extraversion and neuroticism. Polak and McCulough (2006) suggested that gratitude might be an alternative to materialism since it should have the opposite effect on subjective well-being, with important implications for different research areas including social psychology and consumer behavior (Bridger \& Wood, 2017). What follows is an explanation of how gratitude might be related to subjective well-being.

\section{Gratitude}

Gratitude is conceptualized as an emotion and a life orientation in which individuals appreciate and notice positive aspects in their lives (Sirois \& Wood, 2017; Wood, Froh, \& Geraghty, 2010). Gratitude emerges when one recognizes another agent as a source of one's positive aspects in life. The broaden-and-build theory of positive emotions suggests that positive emotions such as gratitude broaden thought repertories and build personal resources (Fredrickson \& Joiner, 2018). When one is grateful, then, there is a tendency to broaden one's mindset and acknowledge, among other aspects, the role of important others in life. Similarly, gratitude also helps build durable resources for well-being such as intrinsic motivation and purposefulness (Bono \& Odudu, 2016).

Given the beneficial consequences of gratitude and the fact that it is an orientation toward appreciating and noticing the positive aspects of life, it has been hypothesized to be related to variables reflecting this positive outlook such as well-being (Puente-Díaz \& Meixueiro, 2016; Wood, Froh, \& Geraghty, 2010) and prosociality (Ma, Tunney, \& Ferguson, 2017). A recent review of the relationship between well-being and gratitude supports this conclusion (Wood, Froh, \& Geraghty, 2010). However, many of the reviewed investigations have limitations. Specifically, there has been inconsistency in the conceptualization of well-being. Whereas some investigations have used positive affect as a proxy of well-being (Froh \& Kashdan, Ozimkowski, \& Miller, 2009), others have used life satisfaction (Wood, Joseph, \& Maltby, 2008). Similarly, to our knowledge, not a single study has examined the influence of gratitude on subjective wellbeing under the hierarchical conceptualization of the construct. The observed inconsistencies in the examination of the effects of gratitude on subjective well-being might since gratitude is still one of the most understudied emotions (Wood, Froh, \& Geraghty, 2010). We want to address these limitations by assessing the influence of gratitude on each of three components of subjective well-being and on the second order 
factor, overall sense of subjective well-being, while controlling for the known effects of extraversion and neuroticism among participants from Mexico (Wood, Joseph, \& Maltby, 2008).

In sum, the purpose of the present investigation is to compare and contrast the influence of gratitude and materialism on subjective well-being under two different conceptualizations: 1) subjective well-being treated as a construct with three different, separate components: life satisfaction, positive and negative affect and 2) subjective well-being treated as a higher order factor, reflected in three first-order factors: life satisfaction, positive affect and negative affect. The following six hypotheses are formulated:

1. Materialism would have a negative effect on positive affect and life satisfaction.

2. Gratitude would have a positive effect on positive affect and life satisfaction.

3. Materialism would have a positive effect on negative affect.

4. Gratitude would have a negative effect on negative affect.

5. Materialism would have a negative effect on overall sense of subjective well-being.

6. Gratitude would have a positive effect on overall sense of subjective well-being.

\section{Participants and Procedure}

Participants were 386 (247 females and 139 males) college students from two private universities in Mexico City and Puebla. The mean age was $22.47(\mathrm{SD}=2.45)$. Students received extra credit for their participation.

Participants completed the questionnaires in small groups of two or three. The questionnaires took between 15 to 20 minutes to complete. All participants were thanked and debriefed after their participation. The present investigation obtained the approval from the institutional human subjects committee.

\section{Measures}

The Satisfaction with Life Scale (SWLS) (Diener, Emmons, Larsen, \& Griffin, 1985). The SWLS is a five-item questionnaire designed to measure satisfaction with life. The questionnaire uses a Likert-type scale and total scores range from 5 to 35. The scale showed adequate psychometric properties for scientific research (e.g., significant loadings and a coefficient of internal consistency of 0.84).

The Scale of Positive and Negative Experience (SPANE) (Diener et al., 2009). The SPANE is a twelve-item questionnaire that includes six items to assess positive feelings and six items to assess negative feelings. Each item is scored on a scale ranging from 1 to 5 , where 1 represents "very rarely or never" and 5 represents "very often or always." The positive and negative scales are scored separately. The scale showed adequate psychometric properties for scientific research (e.g., significant loadings and coefficients of internal consistency above 0.67).

The Material Value Scale (MVS) (Richins, 2004). We used the abbreviated nine- item measure of materialistic values. Each item is scored on a scale ranging from 1 to 5 , where 1 represents "strongly disagree" and 5 represents "strongly agree." The scale possesses good psychometric properties, especially when it is used to measure materialism at the general level. The scale has shown adequate psychometric properties for scientific research in previous studies (e.g., significant loadings and a coefficient of internal consistency of 0.78) (Puente-Díaz \& Cavazos-Arroyo, 2017).

Big Five Inventory (BFI) (Benet-Martínez $\&$ John, 1998). This measure uses 44 short phrases to assess extraversion, agreeableness, conscientiousness, neuroticism, and openness to experience. Respondents rated each of the 44 short phrases on a 5-point scale ranging from 1 (disagree strongly) to 5 (agree strongly). For the purpose of this study, we used an abbreviated scale, four items for each variable, to measure extraversion and neuroticism. Abbreviated measures have been used previously with similar samples (Puente-Díaz \& Cavazos, 
2013). The scale showed adequate psychometric properties for scientific research (e.g., significant loadings and coefficients of internal consistency above 0.67 ).

The Gratitude Scale (McCullough, Emmons, \& Tsang, 2002). This questionnaire contains six items measuring trait gratitude. Items were designed to assess emotional intensity, frequency, and density. Items are rated on a 1 ("strongly disagree") to 7 ("strongly agree") scale. The scale showed adequate psychometric properties for scientific research (e.g., significant loadings and a coefficient of internal consistency of 0.74).

\section{Results}

For the sake of clarity, we organized the results by conceptualization of subjective wellbeing. In the first conceptualization, labeled as model I, subjective well-being is treated as a construct with three separate components. In the second conceptualization, labeled as model II, subjective well-being is treated as second order factor with three first order factors. For both conceptualizations, structural equation models were estimated. We used LISREL 9.1 to conduct all our analyses. We report the $\chi^{2}$, Root Mean Square Error of Approximation (RMSEA), and the Incremental Fit Index (IFI) for each of the analysis conducted. We used the cutoff scores of RMSEA $<0.08$ and IFI $>0.90$ as the minimum acceptable levels of model fit.

\section{Model I}

We first examined the measurement model for the latent variables' materialism, gratitude, extraversion, neuroticism, positive and negative affect and satisfaction with life. Results showed that the model fit was adequate $\chi^{2}=1263.02, p=$ $0.00(d f=719)$, RMSEA $=0.05$ and IFI $=0.94$. Examination of individual parameters revealed that all factor loadings were significant and in the expected direction. Thus, we decided to keep this measurement model and proceed to test the latent model.
Results showed that the model fit was adequate $\chi^{2}=1373.07, p=0.00(d f=726)$, RMSEA $=0.05$ and IFI $=0.93$. Examination of individual parameters revealed that extraversion and neuroticism had significant effects on positive affect and negative affect,

$\gamma=0.36, p<0.05 ; \gamma=0.60, p<0.05$, respectively. More relevant to our investigation, we also found significant effects of materialism and gratitude, in the expected direction, on positive affect, $\gamma=-0.27, p<0.05 ; \gamma=$ $0.27, p<0.05$, respectively, and on satisfaction with life, $\gamma=-0.28, p<0.05 ; \gamma=0.47, p$ $<0.05$, respectively, supporting hypotheses one and two. Results for negative affect showed a significant effect of materialism, $\gamma=0.16, p<$ 0.05 , supporting hypothesis three and a nonsignificant effect of gratitude, $\gamma=-0.03, p>0.05$, failing to support hypothesis four (See Figure 1 for a summary of results). The squared multiple correlations for positive and negative affect, and satisfaction with life were, respectively, 0.30, 0.44 , and 0.31 .

\section{Figure 1}

Summary of results for model I: Separate components conceptualization of subjective well-

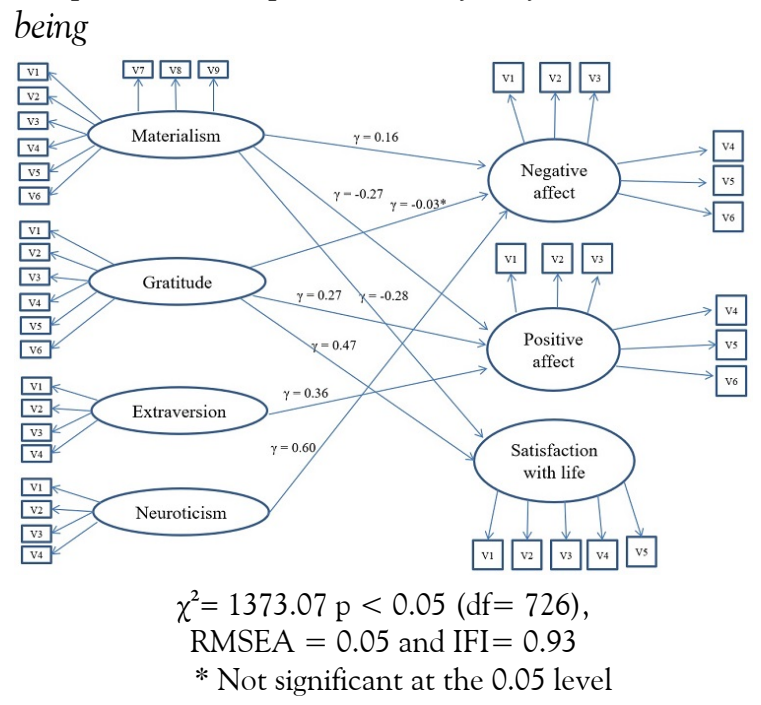

\section{Model II}

We first examined the measurement model for the latent variables' materialism, gratitude, 
extraversion, neuroticism, positive and negative affect and satisfaction with life. It is important to note that the second conceptualization of subjective well-being suggests a second order factor with three latent variables, which are in turn measured by several indicators. Results showed that the model fit was adequate $\chi^{2}$ $=1358.94, p=0.00(d f=727)$, RMSEA $=$ 0.05 and IFI $=0.93$. Examination of individual parameters revealed that all factor loadings were significant and in the expected direction. Thus, we decided to keep this measurement model and proceed to test the latent model.

Results showed that the model fit was adequate $\chi^{2}=1358.94, p=0.00(d f=727)$, RMSEA $=0.05$ and IFI $=0.93$. Examination of individual parameters revealed that extraversion and neuroticism had significant effects on overall sense of subjective well-being, $\gamma=0.21, p<$ 0.05; $\gamma=-0.39, p<0.05$, respectively. More relevant to our investigation, we also found significant effects of materialism and gratitude, in the expected direction, on overall sense of subjective well-being, $\gamma=-0.23, p<0.05 ; \gamma=$ $0.36, p<0.05$, respectively (See Figure 2 for a summary of results). Thus, hypotheses five and six were supported.

\section{Figure 2}

Summary of results for model II: Hierarchical conceptualization of subjective well-being

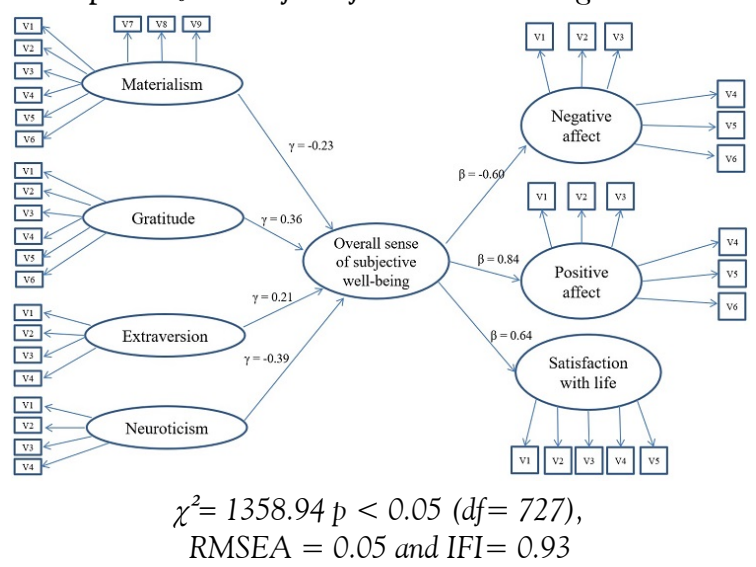

Since this second model proposes a hierarchical structure of subjective well-being, it is possible to examine the indirect effects, via overall sense of subjective well-being, of materialism and gratitude on positive and negative affect and life satisfaction. The results for materialism showed significant indirect effects of materialism on positive and negative affect and life satisfaction, $-0.19, p<0.05 ; 0.14, p$ $<0.05 ;-0.15, p<0.05$, respectively. Similarly, results also showed significant indirect effects of gratitude on positive and negative affect and life satisfaction, $0.30, p<0.05 ; 0.21, p<0.05$; $0.23, p<0.05$, respectively. Lastly, the squared multiple correlations for positive and negative affect, satisfaction with life and overall sense of subjective well-being were, respectively, 0.70 , $0.36,0.41$, and 0.49 .

\section{Discussion}

The purpose of the present investigation was to compare and contrast the influence of gratitude and materialism on subjective wellbeing under two different conceptualizations: 1) subjective well-being treated as a construct with three different, separate components: life satisfaction, positive and negative affect and 2) subjective well-being treated as a higher order factor, reflected in three first-order factors: life satisfaction, positive affect and negative affect. We tested six hypotheses and found support for five of them.

As mentioned earlier, subjective wellbeing has been widely examined (Lucas \& Diener, 2008). However, the rapid growth of knowledge generation has not come without its problems. Several investigations have not conceptualized and operationalized subjective well-being consistently (Busseri, 2015; Busseri \& Sadava, 2011). Inconsistencies in the conceptualization of a construct cause significant problems when one attempts to summarize results from different investigations or when one desires to make conclusions about the influence of a specific predictor on a certain variable. For example, when examining the influence of gratitude on subjective well-being, one does not know if researchers are examining the influence of gratitude on each of three components of the construct, positive and negative affect and 
life satisfaction, within the same model (Froh, Yurkewicz, \& Kashdan, 2009) or only examining the influence of gratitude on life satisfaction (Puente-Díaz \& Meixueiro, 2016). Similarly, in a recent literature review, 12 studies examining the influence of gratitude on subjective wellbeing were identified. Yet, only 4 included all three components of subjective well-being and not a single investigation examined the influence of gratitude on the higher order subjective well-being factor (Wood, Froh, \& Geraghty, 2010). The literature on materialism and subjective well-being shows a similar picture (Burroughs \& Rindfleisch, 2002). Thus, we tried to make a small contribution by conceptualizing and operationalizing subjective well-being consistently and in two different forms in order to examine the influence of materialism and gratitude.

Our results showed that gratitude had a positive effect on positive affect, life satisfaction and overall sense of subjective well-being but a null direct effect on negative affect. Even though the null effect of gratitude on negative affect might come as a surprise, some investigations have found similar results. For example, investigations using experimental (Grant \& Gino, 2010) and correlational designs (Froh, Yurkewicz, \& Kashdan, 2009) have found null effects and non-significant correlations between gratitude and negative affect. Interestingly, however, gratitude had a significant indirect effect, through overall sense of subjective wellbeing, on negative affect. We might conclude, then, that gratitude influences one's overall sense of subjective well-being, which indirectly results in lower levels of negative affect. The beneficial effect of gratitude on subjective wellbeing might be because gratitude strengthens the development of socials ties (Ma, Tunney, \& Ferguson, 2017) and strong social relationships are a robust predictor of subjective well-being (David, Boniwell, \& Conley-Ayers, 2014).

Our investigation also showed that materialism had a negative effect on positive affect, life satisfaction and overall sense of subjective well-being and a positive effect on negative affect. Thus, under both conceptualizations of subjective well-being, materialism was a significant predictor. These results are consistent with other investigations in which the influence of materialism on one or several components of subjective well-being was examined (Burroughs \& Rindfleisch, 2002; $\mathrm{Ku}, 2015)$. To our knowledge, however, the influence of materialism on overall sense of well-being, the hierarchical conceptualization, had not been examined before. We now can conclude that materialism has a significant influence on the three independent components of subjective well-being and on the overall sense of subjective well-being. The negative consequences of holding material values on subjective well-being might come from findings suggesting that the desire to have material possessions is related to poor quality of social relations and low levels of social acceptance (Kasser, 2016). As mentioned earlier, social relationships are a strong predictor of subjective well-being (David, Boniwell, \& Conley-Ayers, 2014).

\section{Limitations}

Our investigation had several limitations. First, we used a correlational design, which does not allow us to establish causality or directionality. Previous research (Polak \& McCullough, 2006) suggests that materialism and gratitude "lead" to lower/higher levels of subjective well-being, yet our investigation cannot establish this. A second limitation is that we used a sample of convenience from two private universities. College students from a private university do not represent well the general population of Mexico. Mexico is a country where income inequalities are considerable. Thus, future research should assess whether materialism and gratitude have the same negative and positive influence, respectively, on subjective well-being among members from lower socioeconomic status. Our guess is that they do, yet this conclusion needs empirical scrutiny. 


\section{Future Directions}

One future direction, especially relevant for the Mexican context, would be to examine how gratitude works under challenging economic circumstances. As mentioned earlier, Mexico has considerable income inequalities, thus a large percentage of the population lives in poverty. It would be interesting to examine if or how people with more difficult living conditions experience gratitude, what they are grateful for and if gratitude is related to important life outcomes such as subjective well-being.

In sum, our investigation was able to examine the effects of gratitude and materialism on subjective well-being under two different conceptualizations of the construct. Materialism had a consistent influence on positive and negative affect, life satisfaction (model 1) and overall sense of subjective well-being (model 2). Gratitude had a significant direct influence on positive affect, life satisfaction (model 1) and overall sense of subjective well-being (model 2 ), suggesting that feeling grateful might not necessarily ward off experiencing negative affect directly.

\section{References}

Benet-Martínez, V., \& John, O. P. (1998). Los Cinco Grandes across cultures and ethnic groups: Multitrait multimethod analyses of the Big Five in Spanish and English. Journal of Personality and Social Psychology, 75(3), 729-750. http://dx.doi.org/10.1037/0022-3 514.75.3.729

Bono, G., \& Odudu, C. (2016). Promoting the development of gratitude to build character and improve society. In D. Carr (Ed.), Perspectives on gratitude: An interdisciplinary approach (pp. 185-198). London, England: Routledge.

Bridger, E. K., \& Wood, A. M. (2017). Gratitude mediates consumer responses to marketing communications. European Journal of Marketing, 51 (1), 44-64. https://d oi.org/10.1108/EJM-11-2015-0810
Burroughs, J. E., \& Rindfleisch, A. (2002). Materialism and well-being: A conflicting values perspective. Journal of Consumer Research, 29(3), 348-370. https://doi.org/10 $.1086 / 344429$

Busseri, M. A. (2015). Toward a resolution of the tripartite structure of subjective well-being. Journal of Personality, 83 (4), 413-428. http:/ /dx.doi.org/10.1111/jopy.12116

Busseri, M. A. (2018). Examining the structure of subjective well-being through metaanalyzing associations among positive affect, negative affect, and life satisfaction. Personality and Individual Differences, 122, 68-71. https://doi.org/10.1016/j.paid.2017. 10.003

Busseri, M. A., \& Sadava, S. W. (2011). A review of the tripartite structure of subjective wellbeing: Implications for conceptualization, operationalization, analysis, and synthesis. Personality and Social Psychology Review, 15(3), 290-314. https://doi.org/10.1177/10 88868310391271

David, S. A., Boniwell, I., \& Conley-Ayers, A. (2014). The Oxford Handbook of Happiness . Oxford, UK: Oxford University Press.

Diener, E. Emmons, R. A., Larsen, R. J., \& Griffin, S. (1985). The satisfaction with life scale. Journal of Personality Assessment, 49(1), 71-75. https://doi.org/10.1207/s1532 7752jpa4901_13

Diener, E., Wirtz, D., Tov, W., Kim-Prieto, C., Choi. D., Oishi, S., \& Biswas-Diener, R. (2009). New measures of well-being: Flourishing and positive and negative feelings. Social Indicators Research, 39, 247-266. https://doi.org/10.1007/978-90-4 81-2354-4 12

Fredrickson, B. L., \& Joiner, T. (2018). Reflections on positive emotions and upward spirals. Perspectives on Psychological Science, 13(2), 194-199. https://doi.org/10. 1177/1745691617692106

Froh, J. J., Yurkewicz, C., \& Kashdan, T. B. (2009). Gratitude and subjective well-being in early adolescence: Examining gender differences. Journal of Adolescence, 32(3), 
633-650. https://doi.org/10.1016/j.adolesce nce. 2008.06.006

Froh, J. J., Kashdan, T. B., Ozimkowski, K. M., $\&$ Miller, N. (2009). Who benefits the most from a gratitude intervention in children and adolescents? Examining positive affect as a moderator. Journal of Positive Psychology, 4(5), 408-422. https://doi.org/10.1080/174 39760902992464

Grant, A. M., \& Gino, F. (2010). A little thanks goes a long way: Explaining why gratitude expressions motive prosocial behavior. Journal of Personality and Social Psychology, 98(6), 946-955. https://doi.org/10.1037/a0 017935

Gruber, J., \& Moskowitz, J. T. (Eds.). (2014). Positive emotion: Integrating the light sides and dark sides. New York, NY: Oxford University Press.

Kasser, T. (2016). Materialistic values and goals. Annual Review of Psychology, 67, 489-514. https://doi.org/10.1146/annurevpsych-122414-033344

$\mathrm{Ku}, \mathrm{L}$. (2015). Development of materialism in adolescence: The longitudinal role of life satisfaction among Chinese youths. Social Indicators Research, 124(1), 231-247. https: //doi.org/10.1007/s11205-014-0787-3

Lucas, R., \& Diener, E. (2008). Personality and subjective well-being. In O. John, R. Robins, \& L. Pervin (Eds.), Handbook of personality. Theory and research (pp. 795-814). New York, NY: The Guilford Press.

Ma, L. K., Tunney, R. J., \& Ferguson, E. (2017). Does gratitude enhance prosociality? A meta-analytic review. Psychological Bulletin, 143(6), 601-635. https://doi.org/10.1037/b ul0000103

McCullough, M. E., Emmons, R. A., \& Tsang, J. A. (2002). The grateful disposition: A conceptual and empirical topography. Journal of Personality and Social Psychology, 82(1), 112-127. http://dx.doi.org/10.1037/ 0022-3514.82.1.112

Polak, E. M., \& McCullough, M. E. (2006). Is gratitude an alternative to materialism? Journal of Happiness Studies,
7(3), 343-360. http://dx.doi.org/10.1007/s1 0902-005-3649-5

Puente-Díaz, R., \& Cavazos, J. (2013). Personality factors, affect, and autonomy support as predictors of life satisfaction. Universitas Psychologica, 12 (1), 41-53. https: //doi.org/10.11144/Javeriana.upsy12-1.pfaa

Puente-Díaz, R., \& Cavazos-Arroyo, J. (2017). Material values: A study of some antecedents and consequences. Accounting Eु Management, 62, 1214-1227. http://dx.d oi.org/10.1016/j.cya.2017.06.008

Puente-Díaz, R., \& Meixueiro, G. (2016). An exploration of the relationships between gratitude, life satisfaction, and importance of helping others among a representative sample of the adult population of Mexico. Cogent Psychology, 3(1). https://doi.org/10.1 080/23311908.2016.1160558

Richins, M. L. (2004). The material values scale: Measurement properties and development of a short form. Journal of Consumer Research, 31 (1), 209-219. http://dx.doi.org/ $10.1086 / 383436$

Sirois, F., \& Wood, A. M. (2017). Gratitude uniquely predicts lower depression in chronic illness populations: A longitudinal study of inflammatory bowel disease and arthritis. Health Psychology, 36(2), 122-132. http://dx.doi.org/10.1037/hea0000436

Wood, A. M., Joseph, S., \& Maltby, J. (2008). Gratitude uniquely predicts satisfaction with life: Incremental validity above the domains and facets of the five factor model. Personality and Individual Differences, 45, 49-54. http://dx.doi.org/10.1016/j.paid.200 8.02.019

Wood, A. M., Froh, J. L., \& Geragthy, A. W. A. (2010). Gratitude and well-being: A review and theoretical integration. Clinical Psychology Review, 30(7), 890-905. https://d oi.org/10.1016/j.cpr.2010.03.005

\section{Notes}

* Research article. 